\title{
Retirement Communities and Housing for the Elderly Editorial to the Special Issue
}

\section{Susan Lucas, Edinboro, Rita Schneider-Sliwa, Basel}

«Youth is everywhere in place. Age, like women, requires fit surroundings. Age is comely in coaches, churches, in chambers of state and ceremony, in council chambers, in courts of justice and historical societies» (EMERson 1862, cited in Achenbaum 1978: 36).

In the spirit of RALPH WALDO EMERSON's oft quoted sentiment regarding the «place» of ageing and the elderly in society, the ageing of North America's and Europe's populations provides the «fit surroundings» for the collection of papers on Retirement Communities and Housing for the Elderly in this special edition of GEOGRAPHica Helvetica. Currently, over 12 percent of both the Canadian and American populations are aged over 65 (U.S. Census Bureau 2001). Approximately 15 percent of Europe's population is aged over 65 and over, with Italy having the largest elderly population (U.S. CENSUs BUREAU 2001). In Switzerland the population over 64 years is $15.5 \%$, comparable to the European standard, and so are the Canton of Zurich (15.25\%) and the Canton of Geneva (14.64\%), whereas the City Canton of Basel has an above average elderly population $(21.6 \%$, according to the BUNDESAMT FÜr STATISTIK 2004). The size of the elderly population in North America and Europe is expected to continue to increase over the next couple of decades as the baby-boom generation enters later life. By the year 2030 projections indicate that 20 percent of North America's and 24 percent of Europe's populations will be aged over 65 (U.S. CENSUs BUREAU 2001).

In an everyday sense the ageing of North America's and Europe's populations are well known. Hardly a week seems to go by without a newspaper story or news report about how the ageing of the population will (negatively) impact society. Two issues in particular, the costs of health care provision and income support policies, have received a great deal of attention and aroused much heated debate in the United States, Canada and many European countries such as Switzerland. The concentration of the elderly in certain places, states or provinces and smaller communities has likewise captured the imagination. Most people in North America are, for example, aware of the concentration of retirees in Florida and Arizona and the development and apparent popularity of Sun City retirement communities in particular and retirement communities in general. In a more mundane sense most urban residents are aware of the existence of nursing homes or apartment buildings containing large proportions of older people within their city of residence. In Switzerland, too, housing for the elderly and the type of living arrangements for the elderly, such as rooming in with family members or non family arrangements, are the topics of continuing public debate.

Laws (1993) convincingly argues that ageist sentiments and public policy created and continue to craft an urban landscape that segregates and concentrates the elderly in very specific spaces. Historically such places have included workhouses and almshouses, but now they include nursing homes, assisted living facilities and state-sponsored chronic care facilities. The development of such concentrations in places and spaces that were generally viewed in a negative light, contends Laws (1993), aided the association of old age with inactivity, poverty, disease and social isolation. In some Swiss cities, this too, is an issue. In the City of Basel, for example, there is a large concentration of retirement homes in that part of town locally called the «Lower Basel» that generally has a poor image (a high proportion of foreigners, redevelopment sites need for special urban planning measures).

The «greying» of the suburbs particularly in North America and the construction of retirement communities, along with the increased exploitation of the senior market (SAwchuck 1995; Moschis et al. 1997) has caused not only the re-distribution of the older population but has also promoted the construction of more positive images of old age. Such images depict older people as happy and healthy members of society, surrounded by friends, with money to spend and the energy to spend it. McHuGH (2000) argues forcefully however that the use of such images to describe later life, though apparently positive, is still troubling. Large or small, retirement communities still segregate older people. Old age is therefore still seen as a distinct part of the life course that is associated with specific spaces. Echoing EMERSON, old age still has «fit surroundings»; it's just that those surroundings are now more pleasant places. Whereas this is true for the North American context where ageing is «big business», the same is not exactly true in the European and Swiss contexts. In the Swiss context, ageing is not «big business» and older consumers remain underserved. This is especially true for private sector housing. While many older Swiss are quite able to afford market rate housing and private housing that has been adapted to meet the specific needs of older people supply remains tight. 
The collection of papers on Retirement Communities and Housing for the Elderly in this special edition of Geographica Helvetica includes a wide range of multidisciplinary research based in Canada, the United States and Switzerland. The papers presented examine indirectly the spatial distribution of the elderly and at the same time the meaning of the residential environments in which the elderly chose to live or are obligated to live because of declining health, limited financial resources or the availability of suitable housing. The examination of the spatial distribution of the elderly population provided by this edition of Geographica Helvetica is indirect as none of the papers purposefully describe patterns of concentration based on age, yet all focus on one of the locations in which the elderly have become concentrated and therefore in totality partially describe where the elderly live. It is necessary however to put a caveat on such a claim - by reading the papers presented it is easy to get the impression that the largest proportion of elderly population lives in agesegregated environments - as Horne indicates in his paper, this is not the case. Most older people age in their own homes, and this is the same in the United States and in Switzerland.

In the first paper in this collection Susan Lucas examines the images used to sell and represent retirement communities. Promotional brochures produced for potential residents by retirement communities are used to determine if and to what extent the notions of successful ageing, defined as the ability to maintain the activity patterns and values of middle age and agelessness are used to market this particular type of age-segregated residential environment. The results show that most of the images used in the retirement community promotional pamphlets describe either the physical environment of each community or the recreational and social amenities available to residents. Images that epitomize successful ageing and agelessness occur almost as frequently and are often mixed with detailed accounts of busy active residents participating in leisure activities, travelling to local attractions, or eating in nearby restaurants. References to the physical and mental decline that often accompanies older age are almost totally absent. When age related decline is mentioned the references are subtle and indirect.

WiLliam R. Horne begins his examination of where seniors move in Brandon, Manitoba by briefly discussing the reasons for and timing of such moves. Income, the level of care needed, familial situation, desire and options available all determine where seniors move. The timing of the move is determined by the timing of the retirement decision, loss of a spouse, difficulty in meeting maintenance costs and changes in the ability of the homeowner to care for themselves in a large single family dwelling. Horne's analysis shows that the options available to seniors who do not move into a care facility or remain in the single family home, are to move to a condominium, mobile home or rental accommodation. Rental options available to seniors are identified as nonprofit housing, public housing, in the form of apartments provided by the Manitoba Housing Authority and private apartments. The most popular option is for seniors to remain in their own homes. Purchasing a condominium or mobile home is also popular. The differing location of the housing options available to Brandon residents means that HoRNE's paper inadvertently provides information about the spatial distribution of Brandon's elderly population. Most of the housing options available to seniors are located close to downtown. More mobile residents who still want a detached owned dwelling can move into a mobile home in a park located just a few kilometres from downtown.

Based on narrative interviews and participant observations Lisa CURCH provides a detailed discussion about the social and environmental factors that affect dietary behaviours among older female residents living in one age-segregated facility. In general, the results show that the provision of meals in a central dining room both liberated the women from food preparation responsibilities and constrained their eating behaviour by removing some of the control they had traditionally exercised over what, where and when they ate. Influences on dietary behaviour that resulted from mobility problems or the stigma attached to the use of assistive devices were grouped together as «person factors» and included the problems some residents experienced walking to the dining room and the fact that some residents disliked assistive devices being brought into the dining room. Sharing a meal with friends in the dining room provided considerable opportunity for social interaction that was welcomed by most residents. As the environment in which residents ate the dining room provided a point of contrast with meals prepared in residents' apartments. Most female residents cooked only simple meals in their apartments as a result of the provision of food in the dining room and most had never used their oven.

In her study «Retirement Housing in Geneva» MARtiNe FreedMan examines the determinants of segregation among the elderly in retirement apartments. Whereas some factors point to personal circumstances, such as the inability to adapt to new situations, there are often determinants that are within the domain of architectural planning. The interplay between micro or individual level factors and the macro context of planning sheds new light on the importance of participa- 
tory planning that would involve the elderly or their associations to a greater degree in the design of private sector, adapted housing.

The issue of participation in the design of adapted housing for the elderly is also taken up by RITA SCHNEIDER-SLIWA. In her study of 3248 persons between the ages of 65-85, elderly people in the Cantons of BaselCity and Basel-Country (Switzerland) are questioned as to their preferences regarding living location, possible residential requirements, size and type of housing/ apartments and living arrangements. The results reflect not only the opinions but the whole life and lifestyle of the so-called older generation. Because of the current independent lifestyle of the elderly and their desire to continue living in a familiar manner and form, the fact that independence is greater respected in society than dependence, the need for respect of the individual and the importance of social cohesion, all possible measures should be taken to ensure mobility and provision of services geared towards the elderly, as well as the preservation of housing arrangements and/or sufficient living space in old age, an area in which the City Canton of Basel has many options for action.

Valesca Zaugg, Joris E. Van Wezemael and André ODERMATT take up this argument of the specific needs of elderly and point to the role in the housing market in generating corresponding supply. Just as the demand for certain type of housing is changing with age, so too, should the supply side respond. According to the authors, this is, however, questionable. They approach the issue of housing supply from the investor's perspective which pursues differential strategies with respect to the ageing society. Whereas non profit investors pursue social aims and are very much orientated towards the elderly, the commercial developers are by and large not interested in investing into adapted housing for the elderly. It is rather the young families that are targeted. Thus, the megatrend of demographic ageing is not accompanied by a similar trend in the housing supply side which attests to market inefficiencies and to the role of the public sector in providing incentives for private builders.

\section{References}

Achenbaum, W.A. (1978): Old age in the New Land. Boulder, CO: Westview Press.

LAws, G. (1993): «The land of old age»: Society's changing attitudes toward built environments for elderly people. - In: Annals of the Association of American Geographers 83: 672-693.

McHugh, K.E. (2000): The «ageless self»? Emplacement of identities in Sun Belt retirement communities. - In: Journal of Aging Studies 14: 103-115.

Moschis, G., Euenun, L. \& A. Mather (1997): Targeting the mature market: Opportunities and challenges. - In: Journal of Consumer Marketing 14: 282-294.

SAwchuck, K.A. (1995): From gloom to boom: Age, identity and target marketing. - In: FeAtherstone, M. \& A. Wernick (eds): Images of Aging: Cultural Representations of Later Life. - London: Routledge: 173-187.

Susan Lucas, Ph.D., Assistant Professor, Department of Geosciences, Edinboro University of Pennsylvania, 230 Scotland Road, Edinboro, PA 16444, U.S.A.

e-mail: slucas@edinboro.edu

Prof. Dr. Rita Schneider-Sliwa, Geographisches Institut der Universität Basel, Abteilung Humangeographie / Stadt- und Regionalforschung, Klingelbergstrasse 27, CH-4056 Basel, Switzerland.

e-mail: Rita.Schneider-Sliwa@unibas.ch 